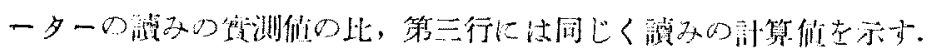

\title{
他物質の及ぼす影響について
}

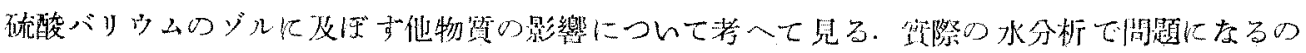

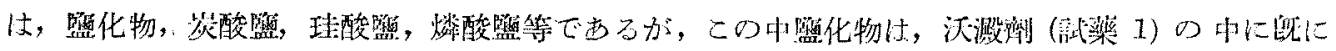

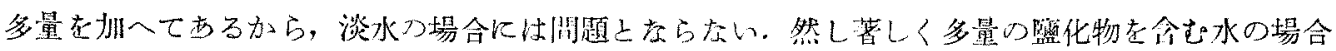

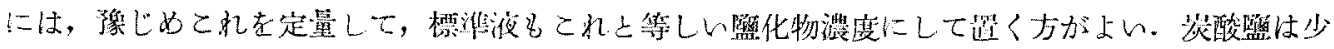

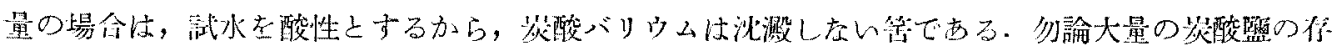

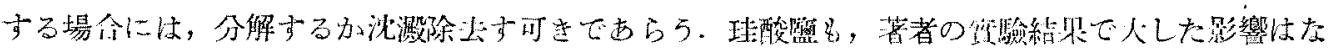

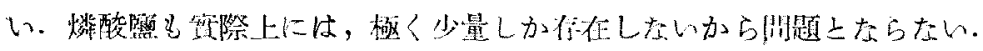

\section{撮 要}

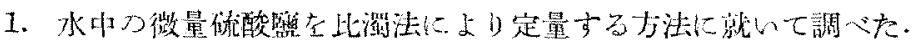

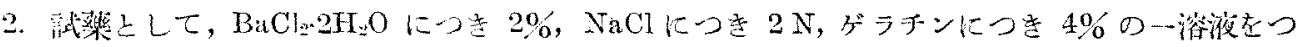

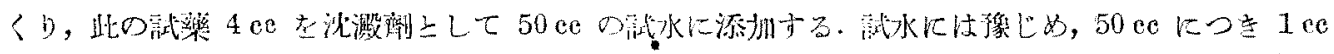

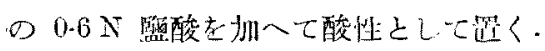

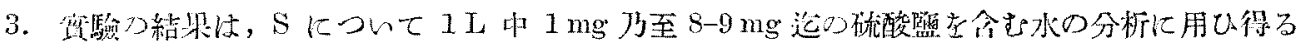

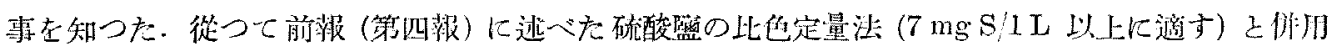
す礼代，水中の硫酸整の分析は都合上く施行し得る蜀である。

\section{諏訪湖結水期日の逃速の解析“*}

\section{藤原驺本, 關口㒋}

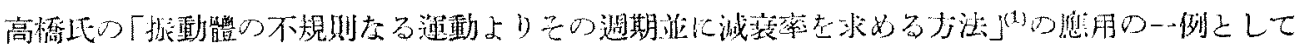

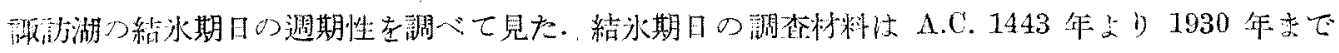

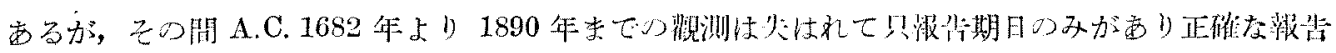

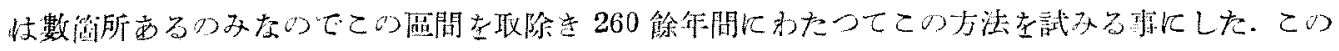

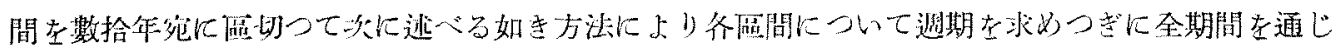

* S. Fujiwhara and Ryo Sekiguti: On the Analysis of the Dat: for the Freczing of Lake Suwa.

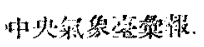

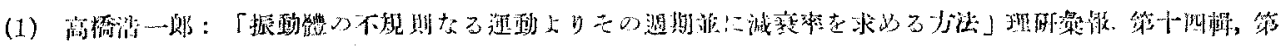

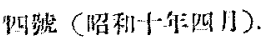

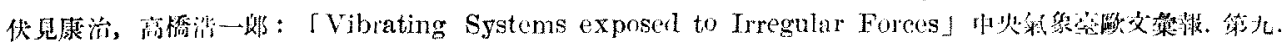

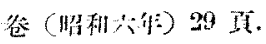


て期期求めた。

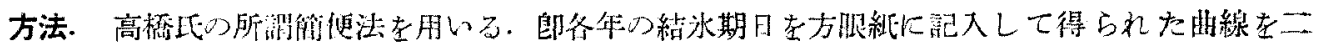

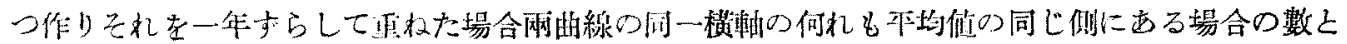

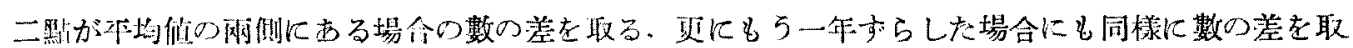

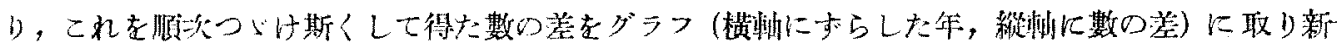

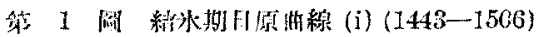

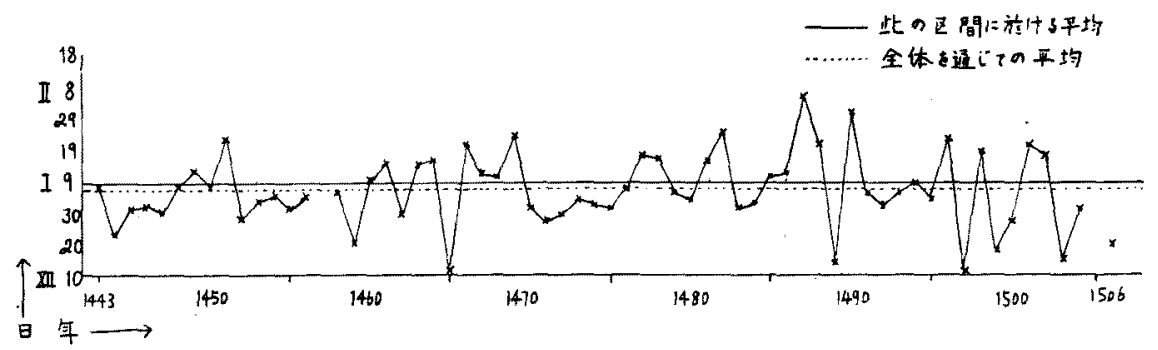

しい断楾在作る・作し一四この方法 在試みただけでは得た訓線仕李だ不 规則であるからてれを二，三四繰返 一すちちに曲線は渪炊規則的になり

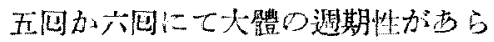
注れる。此の临棌は高橋氏の諭文に 上り最名顯著な症動系の向小振動吉

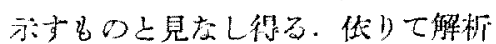

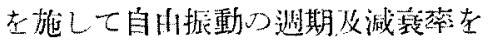
水める。

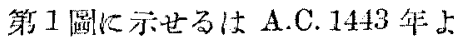
b) 1506 年に至る絬水期日を四宗せ るものでする。

この瞵につんて今逃べをす法に より曲線の型を調心てて欢て緹身さき ○法在 6 回繰返へして第 2 圖に示せ

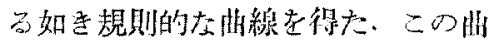
緗は振幅任意な自山振動を表なする のとみなし得る。印 $y=A e^{-a t} \cos \frac{2 \pi}{T}$

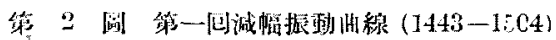

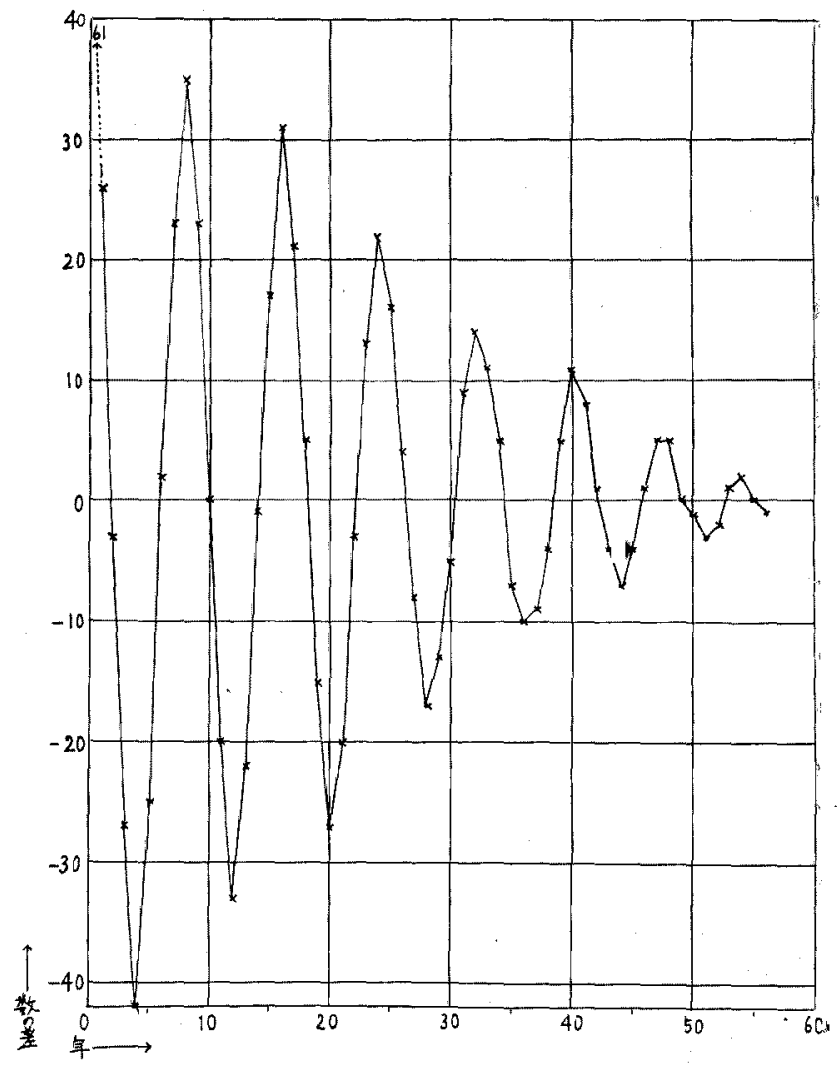




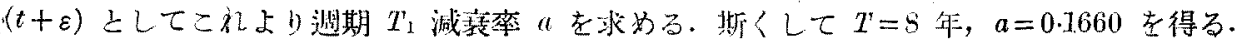

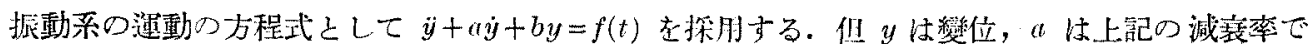
bは $\left(\frac{2 \pi}{T}\right)^{2}-b=\left(\frac{a}{2}\right)^{2}$ り求められる。 $f(t)$ は外力である.この樣な外力により振動するもの上す る.各瞬間に於ける變位，速应及加速度は今り場合はすべて原曲線より知れてるる。郎結水期日を

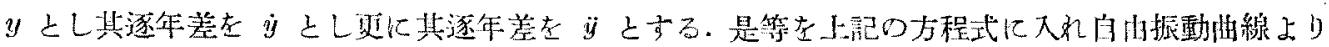

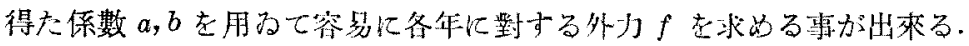

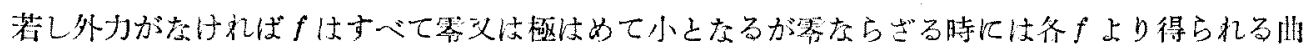
楾は市た一つの振動系を示すもの之みなして 此の新な振動㭌線より今李で上间樣の手段に よりその週期及減趇率が求められる。これ

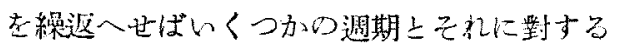
減垒率在得る。以上の方法の際に相等し等 力口二振動柔が西ればをれが同時に現汢れる 事が可能である。其例として A.C. 1221 年 占り 1681 年に至る區閒に於ては最初の結水 旧線に上述の如き䉮便法吉施し・少づ 7 年の週

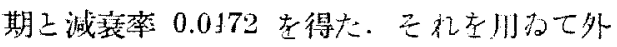

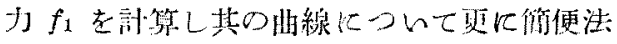

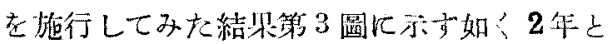
33 年の週期の交つたるのがlogarithmicに減 攱して居るの得た。

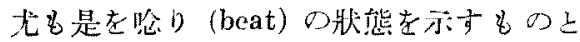
子み在し得る，是老忩りとして解析する上

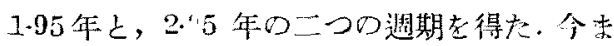
で述べを如きす法により条期間を解析しを結

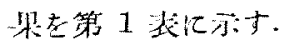

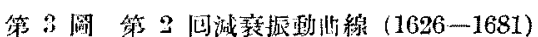

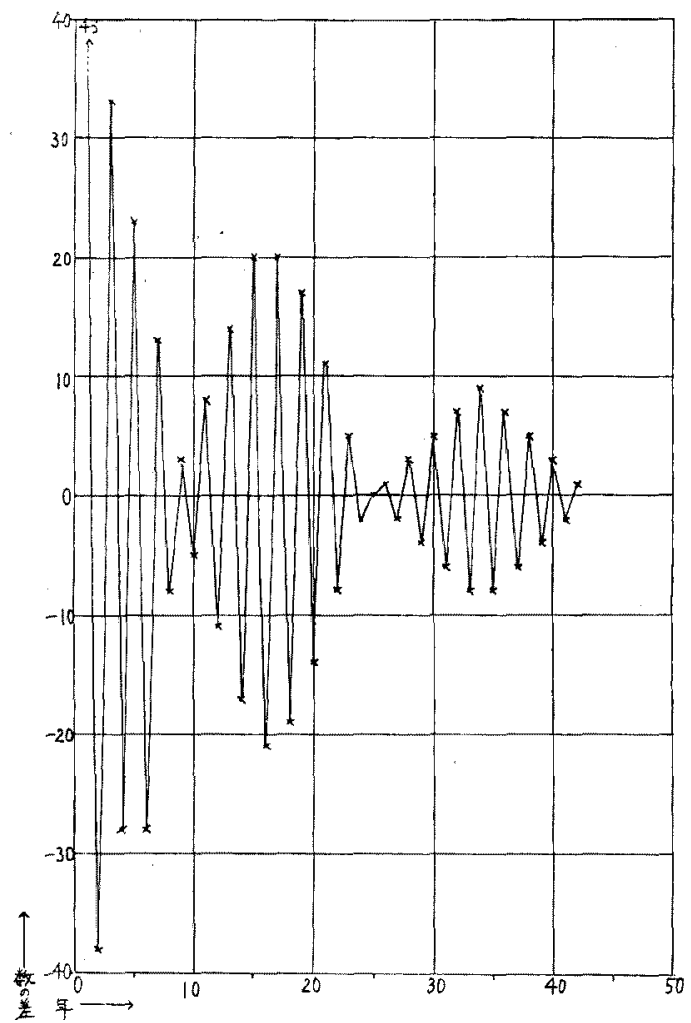

第 1 紧

\begin{tabular}{|c|c|c|c|c|c|c|c|c|}
\hline 期 & 速 罚 & 減変䌛 & IgJ & 減変放 & 則 & 減㱟䇣 & 遇 & 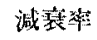 \\
\hline 1443 售-1506 作 & 28 华 & 00507 管 & 80 年 & 0.1660偗 & 180 帒 & 0.0549 脌 & 一手 & 一俰 \\
\hline 1515 禾一代年 & 30 & $0 \cdot(977$ & $\rightarrow$ & - & - & - & - & - \\
\hline 1569 年一1625 住 & 120 & 0.0283 & - & - & - & 一 & - & - \\
\hline 1626 年-1681 往 & $20^{*}$ & 00791 & 35 & 00173 & 70 & 00128 & $330^{*}$ & 0.0791 \\
\hline 1897 年一1930 作 & 50 & 0.0927 & - & - & - & - & 一 & - \\
\hline
\end{tabular}

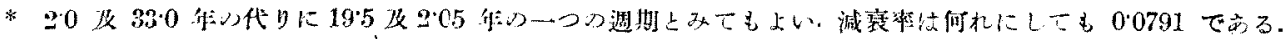




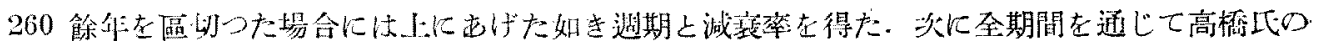

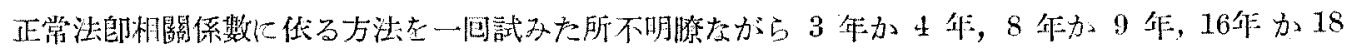

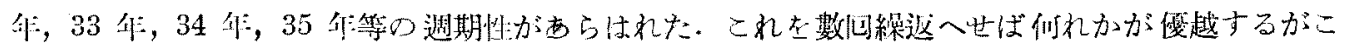

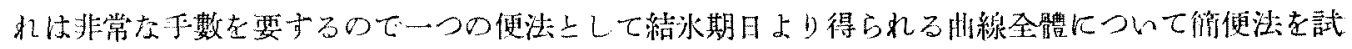

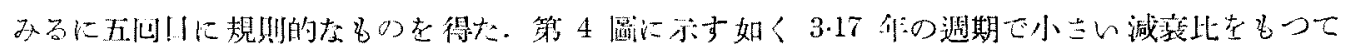

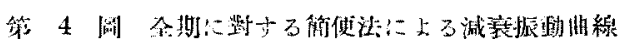

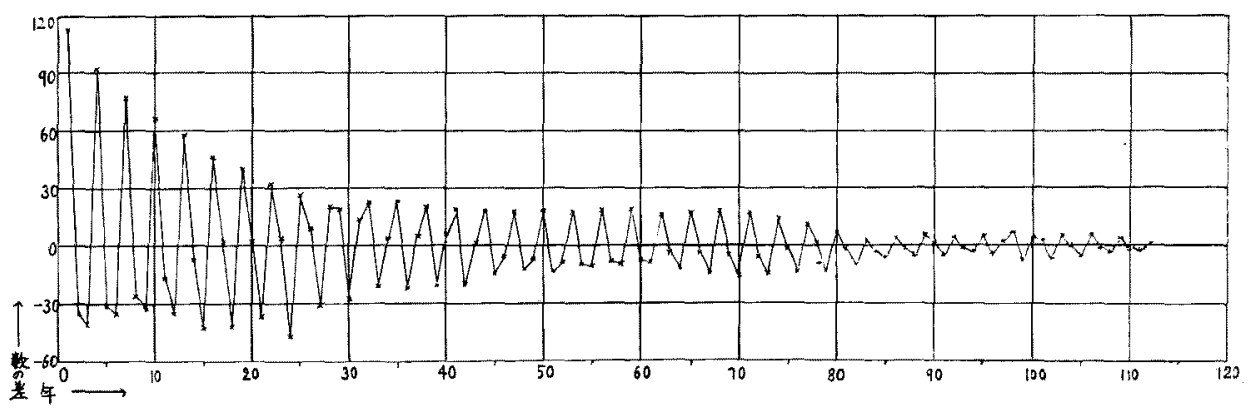

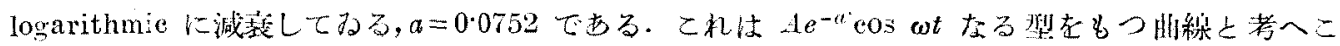

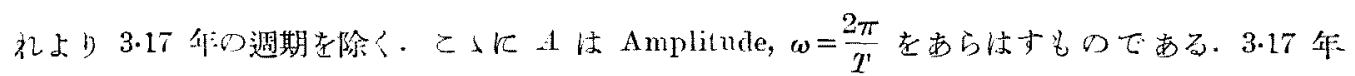

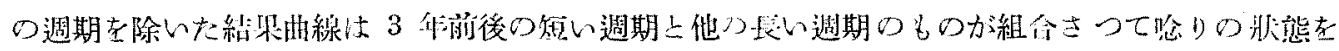

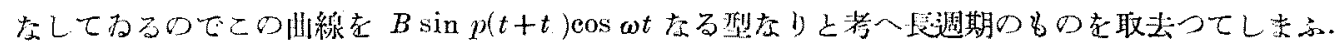

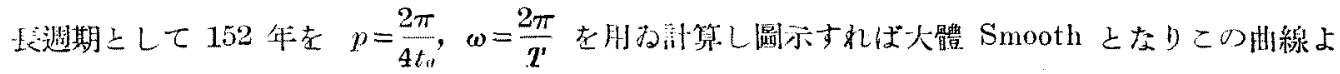

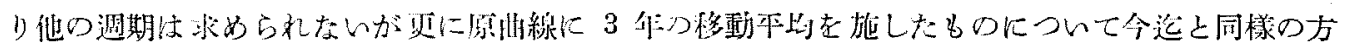

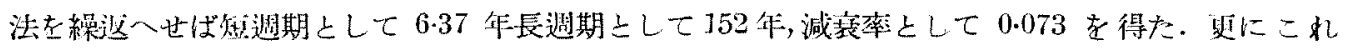

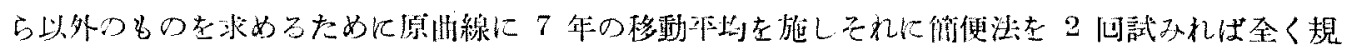
则正しき州楾儿して 85 年の週期之減素率 0.017 をつも0在得大。

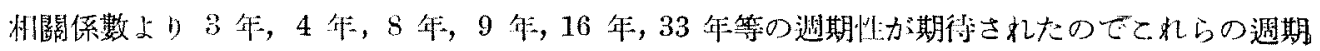

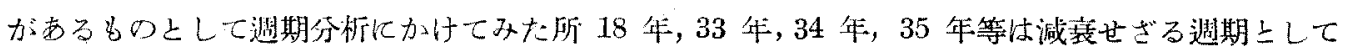

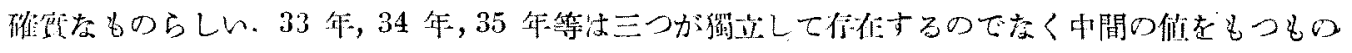
が倠すると落八られる。

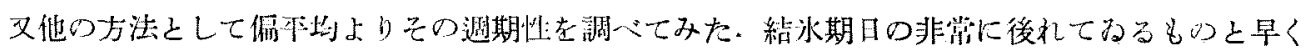

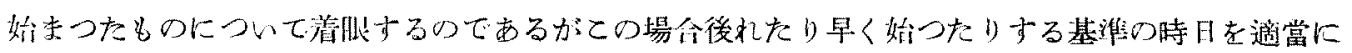

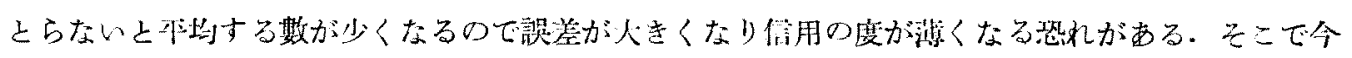

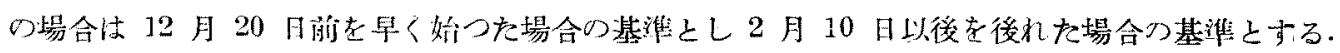

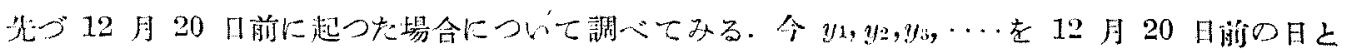




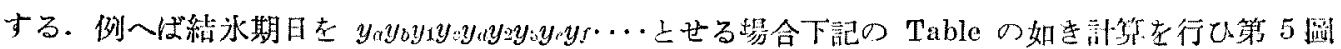
に示せる如き各數豪得た。

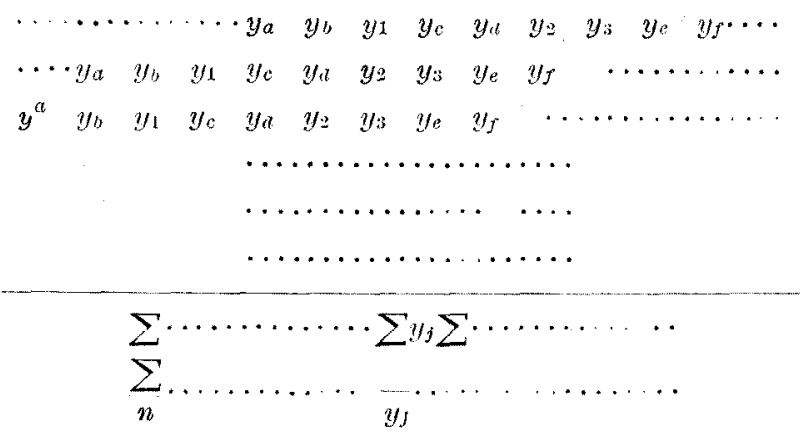

第 5 圆 早緔水を基とした部分本滑の線果

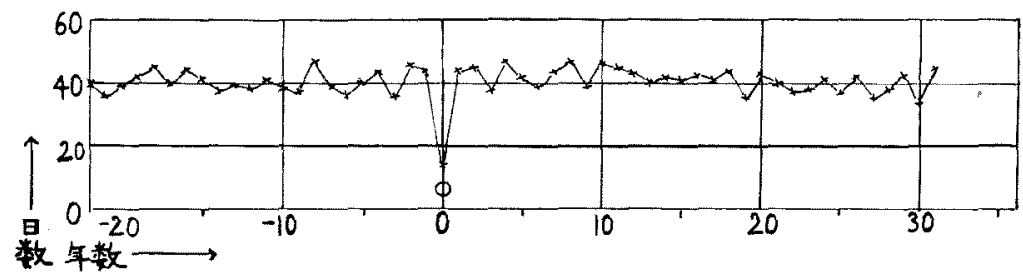

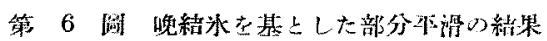

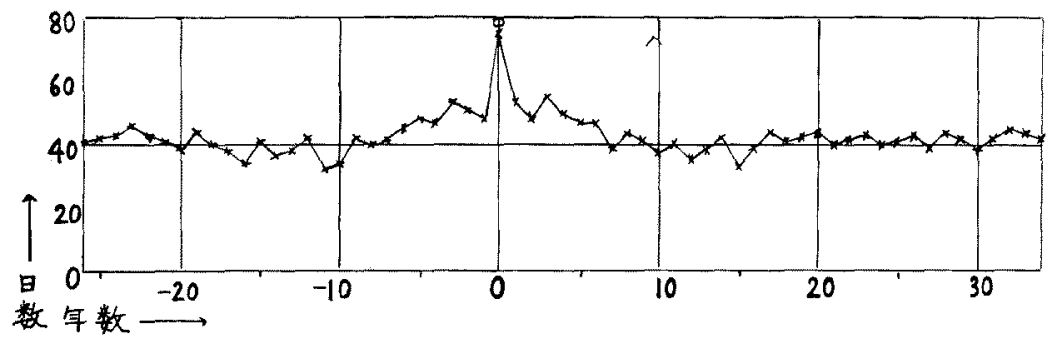

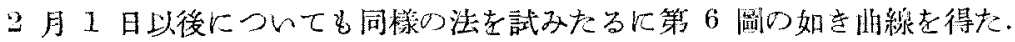

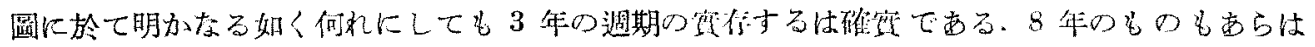
れて居り長期間つものとして 18 年及び 30 年前後がーつの週期として認められる.渔より兒て非 常に結水の後れる時にはそれが偶然として起るのではなくその數年㡐より影響しこの數年後に到る まで影響が及んで居り早く始まる場合には必声しもさう云子事はなく偶然に起り得るらしい。

今まで數通りの方法に上り絬水期日の避速の週期性を調べた所何れの方法によるも碓筫な週期は 約 3 年及び 33 年ですり他の 7 年 8 年等は短期䦌偶然にあらはれたとみられ一つの週期として 探用する事は控へた方がよい樣に思はれる。 